\title{
Boletín Criminológico
}

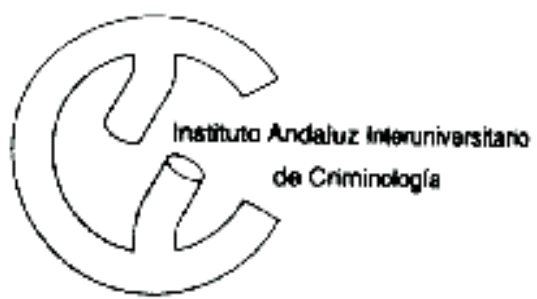

\author{
Director: Per Stangeland \\ Coordinadora: $\mathrm{M}^{\mathrm{a}}$ Auxiliadora Durán Durán \\ Publicado por la Sección de Málaga del IAIC \\ Facultad de Derecho, Universidad de Málaga \\ Campus de Teatinos, 29071 MALAGA. \\ Tel:(95) 2132325 \\ Fax:(95) 2132242
}

En el año 1804 una cuarta parte de la población malagueña murió a causa de la fiebre amarilla. Uno de los desencadenantes de esta tragedia fue la costumbre de sus habitantes de arrojar la basura al cauce del río Guadalmedina, donde los vertidos se acumulaban y descomponían al aire libre. A pesar de ésto, la población mantuvo su costumbre de utilizar el río como vertedero municipal, probablemente por dos razones : no existía otro lugar donde acumular la basura y además su conducta gozaba de completa impunidad.

Actualmente, casi dos siglos después, el río está más limpio, pero el problema, dada la clase y el volumen de desechos generados en nuestro tiempo, es más grave. Los residuos de la civilización moderna incluyen elementos químicos altamente tóxicos, los cuales pueden ser vertidos con la misma impunidad que escombros procedentes de una reforma casera.

La solución a este problema, desde una perspectiva criminológica, consiste en la implantación de un control social eficaz sobre los vertidos ilegales. Sería necesario, en primer lugar, poner a disposición del público más vertederos legales, bien señalizados y de fácil acceso. Segundo, habría de aplicarse la ley contra aquellos que arrojan vertidos ilegalmente : arrojar basura en el barranco más proximo en lugar de dirigirse al vertedero municipal, debería ser más arriesgado a partir de una adecuada vigilancia policial, un proceso eficaz y condenas severas. El nuevo Código Penal estipula en su artículo 325 una pena de entre seis meses y cuatro años de cárcel para infracciones graves contra el medio ambiente. La cárcel tiene un efecto disuasorio probado contra delitos de este tipo.

\section{AUTORES}

José A. Fernández Jurado Carmen $\mathrm{M}^{\mathrm{a}}$ González Almendros Sebastián Sabariego Rivero

\section{INTRODUCCION}

España produce 12 millones de toneladas de desechos al año, lo que supone una media de $0,7 \mathrm{kgs}$. por habitante/día. La composición de la basura es muy heterogénea, dependiendo de múltiples factores, pero se podría aventurar un porcentaje aproximado de 40/ $50 \%$ materia orgánica, $25 / 35 \%$ combustible, $35 / 55 \%$ humedad, $10 / 15 \%$ inerte. Estos residuos pueden provenir del sector primario (agrícolas, ganaderos y forestales) o secundario (industriales y urbanos). Los residuos industria-

\section{VERTEDEROS ILEGALES}

les son más variados que los urbanos, incluyendo elementos tóxicos y peligrosos. En este estudio vamos a centrarnos en el problema de los residuos sólidos urbanos y la situación que plantea su vertido de forma incontrolada.

\section{MARCO LEGAL}

La Constitución en su artículo 45 indica que :

«1.- Todos tienen el derecho a disfrutar de un medio ambiente adecuado para el desarrollo de la persona, así como el deber de conservarlo.
2.- Los poderes públicos velarán por la utilización racional de todos los recursos naturales con el fin de proteger y mejorar la calidad de la vida y defender y restaurar el medio ambiente, apoyándose en la indispensable solidaridad colectiva.

3.- Para quienes violen lo dispuesto en el apartado anterior, en los términos que la ley fije se establecerán sanciones penales o, en su caso, administrativas, así como la obligación de reparar el daño causado.»

Actualmente, en la provincia de Málaga funcionan cuatro vertede-

\section{Boletín Criminológico $N^{o} 16$ Dic. 1995 / Enero 1996 Página 1}


ros legales de Residuos Sólidos Urbanos (R.S.U.): Málaga capital, Antequera, Ronda y La Viñuela, si bien menos del $20 \%$ de los municipios depositan en ellos sus vertidos.

En el presente estudio se intenta dirimir si la responsabilidad

\section{METODOLOGIA}

-Reconocimiento aéreo y estudio fotográfico de Málaga capital y su área metropolitana.

-Consultas a los diversos departamentos de Medio Ambiente de las Administraciones competentes.

-Establecimiento de zonas "tipo" para su estudio particularizado y análisis de su situación geográfica.

-Consulta al Servicio de Protección de la Naturaleza (SEPRONA) de la Guardia Civil.

-Análisis superficial de la composición de los materiales vertidos y estudio fotográfico "in situ".

Además, para la determinación cualitativa de los diferentes tipos de vertederos, se utiliza el denominado muestreo en transepto, también utilizado por el Departamento de Medio Ambiente y Salud Pública del Ayuntamiento de Málaga en un estudio minucioso sobre la situación de los vertederos incontrolados en la capital, llevado a cabo hace unos años. Dicho método consiste en la construcción de un cuadrado de un metro de lado, con listones de madera y subdividido con cuerdas en 25 cuadrados de $20 \mathrm{cms}$. de lado, y su colocación sobre la superficie del vertedero, observándose por cuadrículas los materiales predominantes. Esta acción se repite diez veces manteniendo siempre un lado del cuadrado en común con el anterior. en relación a la existencia de los vertederos ilegales corresponde fundamentalmente a los particulares y empresas privadas que realizan los vertidos, o a la Administración que no pone suficientes medios para garantizar la no producción de vertidos, retirar los vertidos ilegales o cubrir vertederos no autorizados, así como para sancionar a los responsables.

\section{ZONAS INVESTIGADAS}

El presente estudio eligió las siguientes zonas para estudiar la presencia de vertederos ilegales e incontrolados:

\section{1)Málaga capital.}

2)Zona litoral (Marbella).

3)Vélez y su comarca.

4)Una zona interior rural

\section{(Alameda).}

1. En Málaga capital, el depósito de residuos domésticos en el vertedero de los Ruices ha paliado en gran medida el problema de los vertederos ilegales de este tipo, a pesar de lo cual se observan numerosos vertederos de pequeña proporción en casi todo el extrarradio de la capital. Destaca el penoso estado que presentan el polígono industrial del Guadalhorce, alrededor del cual se acumulan indiscriminadamente residuos industriales, y el área conocida como playa de la Térmica, a consecuencia de vertidos de tipo escombrera que, si bien no plantean graves problemas de contaminación, causan un importante impacto paisajístico sobre el medio. $\mathrm{Ni}$ empresas privadas ni particulares tienen reparos a la hora de efectuar vertidos en estos lugares, convirtiéndose en los vertederos más voluminosos de la zona. Se observan diferencias entre la zona oeste y la zona este, con mayor deterioro alrededor de la primera debido, quizás, al menor coste del terreno.
Un vuelo en helicóptero sobre el área metropolitana de Málaga permitió comprobar la existencia de numerosos vertederos, sobre todo en los alrededores de polígonos industriales y en el extrarradio, en un entorno entre 0 y 4 $\mathrm{kms}$. de la zona urbanizada. Desde el aire se observan superficies de textura especial formadas por conos, producidos por los volquetes de los camiones que trasladan residuos, siendo evidente que no se trata sólo de vertidos consecuencia de obras domésticas particulares, sino que también participan empresas propietarias de camiones.

2. En Marbella el núcleo urbano se encuentra bastante limpio, pero los vertidos de basuras se realizan en vertederos ilegales controlados. Así, se constata que las inversiones se han destinado a mejorar numerosos aspectos de la ciudad, pero no a construir una planta de R.S.U. En Marbella y su comarca no existe ni un sólo vertedero legal, aunque cuando se consulta a los ayuntamientos éstos indican que el problema está en vías de solución. De hecho, es posible observar escombreras tanto en lugares de paso muy concurridos (por ejemplo, el cruce de Benahavis), como en zonas de alto nivel económico. Hemos observado una escombrera proviniente de las viviendas de la zona junto al palacio de un famoso rey árabe.

3. La zona de Vélez estableció un acuerdo para la utilización del vertedero de los Ruices de Málaga, pero dado el alto coste que suponía el traslado hasta éste, se han vuelto a realizar vertidos ilegales controlados, efectuándose otros en los márgenes del río. En el término de Vélez se observa una mayor presencia de vertidos de tipo industrial.

4. En la zona interior, Alame$\mathrm{da}$, se han localizado cuatro ver-

\section{Boletín Criminológico}


tederos ilegales controlados, $\mathrm{y}$, en general, ausencia de otros vertidos en el resto del término municipal.

\section{SANCIONES}

LaAgencia de Medio Ambiente (AMA) de la Junta de Andalucía señala que más del $90 \%$ de los vertederos existentes en la provincia de Málaga son ilegales. Durante 1994 se abrieron 54 expedientes sancionadores a ayuntamientos de la provincia por depósito de R.S.U. en vertederos ilegales controlados, tras la presentación de denuncias, buena parte de las cuales proceden del SEPRONA o de la Policía Autónoma. La mayoría de estos expedientes han sido sobreseídos, ya que los municipios se han adherido al Plan Director de R.S.U., cuyo objetivo es legalizar la situación. Unicamente la Mancomunidad de municipios de la Costa del Sol y Vélez Málaga tienen expedientes en curso al no haberse unido a este Plan Director. Una vez tramitados, dichos expedientes serán enviados al Ministerio Fiscal ante la imposibilidad legal de la AMA para sancionar a los ayuntamientos.

Respecto de las denuncias presentadas por la Guardia Civil, especialmente por el SEPRONA, contra ciudadanos que han sido sorprendidos arrojando vertidos, al ser competencia de los ayuntamientos sancionar estas infracciones la AMA les remite las denuncias a través del Gobierno Civil, principalmente. En caso de que los vertidos afecten a ríos, arroyos o sus cauces, son remitidas a la Confederación Hidrográfica. Por tanto, se da la paradoja de que los mayores infractores (ayuntamientos) son competentes para sancionar a los particulares que realizan vertidos ilegales.
En cuanto a la remisión de los expedientes al Ministerio Fiscal, esta vía no resulta adecuada al no cumplir casi nunca la existencia de vertederos ilegales el tipo legal de delito ecológico según el actual Código Penal. De este forma, si la AMA no puede sancionar a los infractores y las restantes vías legales tropiezan con dificultades, la situación práctica es de total impunidad.

\section{CONCLUSIONES}

Los residuos de basura doméstica generados a diario en la ciudad son recogidos prácticamente en su totalidad por el ser- vicio municipal de recogida de basuras, de forma estructurada : vivienda-bolsa-contenedor-camión-vertedero, siendo este último eslabón el que presenta el principal problema, ya que en la mayoría de los casos los residuos son vertidos en lugares controlados, pero de forma que no se atiene a la ley.

La Junta de Andalucía cifra en más de 200 los puntos de la provincia de Málaga donde se localizan vertederos ilegales. Según lo observado a lo largo de este trabajo el número podría duplicarse, y ello sin tener en cuenta los numerosos vertederos ilegales pequeños de menos de $500 \mathrm{~m}$.

\section{DEFINICIONES}

Vertedero legal : cumple toda la normativa vigente (laboral, medioambiental, de seguridad, etc.).

Vertedero privado : situado en una propiedad privada, su titular consiente en recibir materiales inertes (escombros fundamentalmente), para rellenar y poner al nivel deseado una superficie de terreno.

Vertedero ilegal controlado : no cumple las exigencias legales para su instalación y utilización, pero su uso ha sido oficializado por los ayuntamientos ante la inexistencia de vertederos legales. En él depositan basuras las empresas de recogida de residuos de la ciudad y también particulares y empresas privadas.

Vertedero ilegal incontrolado : es utilizado por particulares o empresas privadas sin relación con la Administración. Su instalación y uso no cumple con la normativa vigente y el vertido se produce de forma clandestina. 
cuadrados.

En cuanto al control formal se ha podido constatar que los cuerpos de seguridad del Estado mantienen una vigilancia constante en este tema, denunciando los vertidos ilegales que observan aunque no en todas las ocasiones, ya que tendrían que denunciar todos los días a determinados ayuntamientos.

Durante el trabajo de campo en vertederos se observó que algunas personas se dedican a rescatar objetos que pueden ser reutilizados, lo que lleva a pensar que con una mejor selección en el domicilio y disponiendo del cauce de recogida adecuado se podrían aprovechar muchos materiales.

Desde el punto de vista sociolaboral, la eliminación de vertederos ilegales y la creación de otros acordes con la ley podría ser una actividad que generase numerosos puestos de trabajo, no siendo incompatible con la oferta de pla- zas para jóvenes objetores de conciencia preocupados por la regeneración del medio ambiente en lugares seriamente afectados por la existencia de residuos.

Algunas sugerencias orientadas a la desaparición de los vertederos serían las siguientes:

-Mayor coordinación de los diferentes niveles de la Administración (local, autonómico y estatal).

-Financiación adecuada, ya que la creación de plantas de R.S.U. exige grandes inversiones.

-Campañas de concienciación ciudadana destinadas a un mejor uso de los vertederos legales por parte de los particulares, una vez que existiesen en todos los lugares.

-Eliminación de vertederos ilegales de forma progresiva.

-Establecimiento de un procedimiento sancionador más ágil.

-Potenciar las patrullas del SEPRONA de la Guardia Civil y las Patrullas Verdes de la Policía Lo- cal.

-Analizar las características de terrenos que potencialmente pudieran albergar un vertedero, en su valor ecológico, cultural, económico, geográfico, etc., pudiendo ser consideradas adecuadas para el vertido de escombros no-tóxicos las numerosas canteras de arcilla y caliza abandonadas existentes en el término municipal y en toda la provincia, que posteriormente podrían ser reforestadas.

La responsabilidad de los particulares y las empresas privadas en este tema queda subsumida en la mayor y más grave responsabilidad de la Administración, que no pone a disposición de aquéllos los lugares adecuados para efectuar el depósito de los residuos. No obstante, es reprobable y delictivo el comportamiento de numerosos particulares y empresas privadas que depositan residuos de forma ilegal, en lugares en los cuales éstos suponen un grave deterioro del medio ambiente.

El Boletín Criminológico ofrece un breve resumen de trabajos de investigación llevados a cabo en el Instituto Andaluz Interuniversitario de Criminología. Su edición es mensual y la subscripción gratuita.

Quiero recibir el Boletín Criminológico

Nombre

Teléfono

Dirección 